Check for updates

Cite this: RSC Adv., 2018, 8, 9334

Received 2nd February 2018

Accepted 27th February 2018

DOI: 10.1039/c8ra01018h

rsc.li/rsc-advances

\section{Controllable thermal and $\mathrm{pH}$ responsive behavior of PEG based hydrogels and applications for dye adsorption and release}

\begin{abstract}
Hailong Huang, (D) Lifeng Hou, Feng Zhu, Juan Li* and Min $\mathrm{Xu}^{\star}$
A series of controllable thermal and $\mathrm{pH}$ dual-responsive copolymeric hydrogels (PMA) were prepared by a one-pot reaction with poly(ethylene glycol) methyl ether acrylate (PEGA), 2-methoxyethyl acrylate (MEA) and acroleic acid (AA). The hydrogels exhibited good mechanical properties and a sensitive response to $\mathrm{pH}$ and temperature. Besides, the Lower Critical Solution Temperature (LCST) of the hydrogels can be adjusted from $37{ }^{\circ} \mathrm{C}$ to $58{ }^{\circ} \mathrm{C}$ by changing the content of AA. The hydrogels also showed excellent selective adsorption properties. The maximum adsorption quantity of organic cationic dye brilliant green and methylene blue were $0.49 \mathrm{mg} \mathrm{mg}^{-1}$ and $0.42 \mathrm{mg} \mathrm{mg}^{-1}$ respectively, much better than previous reports. Furthermore, using the thermal and $\mathrm{pH}$ responsibility, the PMA hydrogels can release the adsorbed molecules with control. Nearly 95\% of carriers could be released at pH 4.01 and $65{ }^{\circ} \mathrm{C}$ over $8 \mathrm{~h}$. The regeneration ability makes the materials easy to reuse many times. Due to these properties, these dual-responsive hydrogels have great potential applications in various fields for adsorption, drug delivery, release and tissue engineering.
\end{abstract}

\section{Introduction}

Polymer hydrogels are cross linked three-dimensional polymeric networks. ${ }^{1-3}$ They can absorb a great quantity of water and remain mechanically stable without dissolving. In recent years, hydrogels show good performance in developing functional materials such as shape memory polymers, ${ }^{4-7}$ selfhealing materials, ${ }^{8}$ sensor units, ${ }^{9}$ super capacitors ${ }^{10}$ and drug delivery vectors. ${ }^{11-13}$ Thus, the applications of polymer hydrogels have spread to many fields. One of the most studied forms is stimuli-response hydrogels, ${ }^{14}$ which can respond to environmental conditions like $\mathrm{pH}$, temperature, magnetic field, light and so on. Among them, the thermal-response property is the most widely studied. Different kinds of temperature responsive materials have been developed. Poly $(\mathrm{N}$-isopropylacrylamide) (PNIPAM) is one of the representatives for the LCST around $32{ }^{\circ} \mathrm{C}$, closing to the human body temperature. Thus, PNIPAM has been introduced to various hydrogels as the unit for offering the temperature responsiveness. ${ }^{15,16}$ However, most of the PNIPAM composite hydrogels show poor mechanical property, delayed or slow response, which limited their application as functional and biological materials. Hence, it is important to develop alternative structure which could have the excellent thermal-sensitiveness, good mechanical property and reduced hydrogen-bond. In 2012,

School of Physics and Materials Science, Shanghai Key Laboratory of Magnetic Resonance, East China Normal University, No. 3663 North Zhongshan Road, Shanghai 200062, P R China.E-mail:xumin@phy.ecnu.edu.cn; jli@phy.ecnu.edu.cn
Liu's group ${ }^{17}$ reported the poly(2-methoxyethyl acrylate-copoly(ethylene glycol) methyl ether acrylate) (P(MEA-co-PEGA)) by RAFT dispersion polymerization in water which showed good thermal stimuli-response. They successfully synthesized copolymer hydrogels with narrow range temperature response and linear relationship between LCST and composition through adjusting the contents of monomers, although the mechanical property of such hydrogels was still low. Besides, RAFT requires specify chain transfer agent and initiator, which play important roles in LCST controlling.

In this work, a simple one-pot method was used to prepare a series of dual-responsive hydrogels based on tri-copolymer of PEGA, MEA and AA by conventional free radical polymerization. The polymer hydrogels showed excellent $\mathrm{pH}$-sensitive and temperature-sensitive ability simultaneously. By changing the content of AA, the LCST of the hydrogels can be adjusted from $37^{\circ} \mathrm{C}$ to $58{ }^{\circ} \mathrm{C}$. Due to the functional group and structure, the PMA hydrogels showed excellent selective adsorption property. Moreover, by adjusting the $\mathrm{pH}$ and temperature, the adsorptions can be released almost completely. These properties ensure the PMA hydrogels have great potential applications in various aspects as adsorption, drug delivery, release and tissue engineering.

\section{Experimental sections}

\section{Materials}

2-Methoxyethyl acrylate (MEA, 98\%), poly(ethylene glycol) methyl ether acrylate (PEGA, $M_{\mathrm{n}}=480$ ), acrylic acid (AA, 98\%) 
were purchased from Sigma-Aldrich. Ammonium persulphate (APS) was purchased from Shanghai-Aladdin.

\section{Synthesis}

Poly(2-methoxyethyl acrylate-poly(ethylene glycol) methyl ether acrylate) hydrogels (PM). $1.504 \mathrm{~g}$ PEGA was dissolved in $5.186 \mathrm{~g}$ water, and then $0.592 \mathrm{~g}$ MEA was added. The mixture was stirred for 30 min until completely dissolved. $6 \%$ APS was added to the solution and the reaction was carried out at $50{ }^{\circ} \mathrm{C}$ for 4 hours under stirring. Then the hydrogel was formed and cooled to the room temperature.

Poly(2-methoxyethyl acrylate-poly(ethylene glycol) methyl ether acrylate-acrylic acid) hydrogels (PMA-1). $1.504 \mathrm{~g}$ PEGA was dissolved in water, and then $0.592 \mathrm{~g}$ MEA was added. The mixture was stirred for $30 \mathrm{~min}$ until completely dissolved. Then, different content of AA and a small amount of APS were added to the solution. The reaction was carried out at $50-60{ }^{\circ} \mathrm{C}$ for $6-$ $8 \mathrm{~h}$ under stirring. Then the hydrogel was formed and cooled to the room temperature. In this paper, the PMA hydrogels with different content of AA were named as PMA-1 and PMA-2 as shown in Table 1.

\section{Characterization}

FTIR spectra. The experiments were performed on NicoletNexus 670 spectrophotometer at room temperature. The dried gels were triturated with $\mathrm{KBr}$ at the ratio of $1: 100$.

NMR spectra experiments. High resolution solution ${ }^{13} \mathrm{C}$ NMR spectrum was performed on a Varian $700 \mathrm{MHz}$ at room temperature. Solid-state ${ }^{13} \mathrm{C}$ cross-polarization/MAS NMR spectrum were performed at room temperature on Bruker $300 \mathrm{M}$ (spinning rate set as $5 \mathrm{kHz}$, cross polarization time $=1.0 \mathrm{~ms}$ ).

Lower critical solution temperature. The experiments were studied by turbidimetry on a Hitachi U-3010 UV-Vis spectrometer. The temperature was detected from $25{ }^{\circ} \mathrm{C}$ to $75{ }^{\circ} \mathrm{C}$. The temperature at $50 \%$ transmittance of thermal transition was taken as the LCST.

Mechanical property of hydrogels. Hydrogels were prepared as expected shape ( $15 \mathrm{~mm}$-thick cylindrical molds). The linear ramp force was designed as $1 \mathrm{~N} \mathrm{~min}^{-1}$ to test the hydrogels. The compressive modulus was calculated by the slope of the stressstrain curve in the linear region.

Swelling property. In order to obtain the hydrogels' swelling properties, the dried hydrogels were immersed into water at $25{ }^{\circ} \mathrm{C}$, till reaching equilibrium of swelling. The swollen hydrogels were weighed after the excess of water on the surfaces absorbed by filter paper. The swelling radio $\left(\mathrm{g} \mathrm{g}^{-1}\right)$ was calculated using eqn (1).

Table 1 Different content of PMA hydrogels

\begin{tabular}{lllllll}
\hline Sample & PEGA $(\mathrm{g})$ & MEA $(\mathrm{g})$ & AA $(\mathrm{g})$ & $\mathrm{H}_{2} \mathrm{O}(\mathrm{g})$ & APS $(\%)$ & Time $(\mathrm{h})$ \\
\hline PM & 1.504 & 0.592 & - & 5.186 & $6 \%$ & 4 \\
PMA-1 & 1.504 & 0.592 & 0.301 & 5.186 & $6 \%$ & 6 \\
PMA-2 & 1.504 & 0.592 & 0.575 & 5.186 & $6 \%$ & 6
\end{tabular}

$$
W=\left(W_{\mathrm{s}}-W_{\mathrm{d}}\right) / W_{\mathrm{d}}
$$

$W_{\mathrm{s}}$ and $W_{\mathrm{d}}$ are the weights of the hydrogels at swelling and dried, respectively.

pH responsiveness. The swelling ratio of hydrogels in PBS with $\mathrm{pH} 4.01$, pH 7.4 and $\mathrm{pH} 9.18$ were measured, respectively. The swelling ratio of hydrogels at different $\mathrm{pH}$ solutions were measured using the same method as follows: the dried samples were immersed into $\mathrm{pH}=4.01$ solution to reach equilibrium. Then the swollen hydrogel was transferred into $\mathrm{pH}=9.18$ solution to reach new equilibrium. The processes were repeated for 5 times and the swelling equilibrium was calculated each time.

Temperature responsiveness. The swelling ratio of hydrogels at different temperature was measured respectively using the same method as follows: the dried samples were immersed into $25{ }^{\circ} \mathrm{C}$ aqueous solution to reach equilibrium. Then the swollen hydrogel was transferred into $80^{\circ} \mathrm{C}$ aqueous solution to reach new equilibrium. The processes were repeated for 5 times and the swelling equilibrium was calculated each time.

\section{Adsorption}

To investigate the adsorption property, $10 \mathrm{mg}$ dried PMA-2 hydrogel was put into organic pigment (brilliant green and methylene blue) solutions with different concentration from $0.0498 \mathrm{mg} \mathrm{mL}^{-1}$ to $1.7778 \mathrm{mg} \mathrm{mL}^{-1}$, at room temperature for $72 \mathrm{~h}$. The concentration of brilliant green and methylene blue in the solution were determined by UV at $623 \mathrm{~nm}$ and $664 \mathrm{~nm}$, respectively. The adsorption capacity $\left(Q_{\mathrm{e}}\right)\left(\mathrm{mg} \mathrm{mg}^{-1}\right)$ was calculated as eqn (2).

$$
Q_{\mathrm{e}}=\frac{\left(C_{0}-C_{\mathrm{e}}\right) V}{m}
$$

$Q_{\mathrm{e}}$ is the adsorption capacity of organic pigment. $C_{0}$ and $C_{\mathrm{e}}$ are initial and equilibrium concentrations of organic pigment. $V$ is the volume of solution, and $m$ is the weight of the dried hydrogels.

The adsorption kinetics were investigated as follows: $10 \mathrm{mg}$ dried PMA-2 hydrogel was added into $5 \mathrm{~mL}$ organic pigment solution $\left(1.7778 \mathrm{mg} \mathrm{mL}^{-1}\right)$ at room temperature and then the samples were taken out at predetermined time ranging from $5 \mathrm{~min}$ to $72 \mathrm{~h}$. The adsorption capacity $Q_{t}\left(\mathrm{mg} \mathrm{mg}^{-1}\right)$ was calculated according to eqn (3).

$$
Q_{t}=\frac{\left(C_{0}-C_{t}\right) V}{m}
$$

$Q_{t}$ is the adsorption capacity of organic pigment at different time. $C_{t}$ and $C_{0}$ are initial and equilibrium concentrations of organic pigment, respectively. $V$ is the volume of solution, and $m$ is the weight of the dried hydrogels.

\section{Release and regeneration}

The release behaviour of hydrogels was studied at different $\mathrm{pH}$ and temperature. The PMA- 2 hydrogel was put into the brilliant green solution and kept $72 \mathrm{~h}$ till adsorption equilibrium. Then the loaded hydrogel was put into $30 \mathrm{~mL}$ PBS solutions with 
different $\mathrm{pH}(\mathrm{pH}=4.01, \mathrm{pH}=7.4 \text { and } \mathrm{pH}=9.81)^{18}$ at $25{ }^{\circ} \mathrm{C}$. Periodically, $5 \mathrm{~mL}$ of solution was collected and the same volume of fresh PBS solution was added to keep the volume of the solution. The collected solution was detected by UV at $623 \mathrm{~nm}$ to measure the concentration of releasing brilliant green. The effect of temperature on release was researched from $25{ }^{\circ} \mathrm{C}$ to $80{ }^{\circ} \mathrm{C}$ with $\mathrm{pH} 4.01 \mathrm{PBS}$ solution. The process was repeated to calculate the content of releasing brilliant green.

Regeneration is an attractive property for adsorption materials. To research the regeneration properties, PMA-2 hydrogel was used to adsorb and release brilliant green in pH 4.01 PBS solution at $65{ }^{\circ} \mathrm{C}$. The adsorption and releasing process was repeated 5 times and the concentration was calculated.

All the adsorption and releasing experiments were performed in three repetitions to ensure the accuracy of data and the error bars were shown in the corresponding figures.

\section{Results and discussion}

\section{Characterization}

A series of tri-copolymer hydrogels was synthesized by one-pot reaction with 2-methoxyethyl acrylate, poly(ethylene glycol) methyl ether acrylate and acroleic acid. The AA was introduced into the system to gain a controllable thermal and $\mathrm{pH}$ dualresponsive copolymeric hydrogels. The proposed processes for PMA-1 and PMA-2 were shown in Scheme 1.

The FTIR spectra of AA, MEA, PEGA, PM, PMA-1 and PMA-2 were displayed in Fig. 1. The characteristic peaks of AA were observed, $-\mathrm{OH}$ stretching at $3450 \mathrm{~cm}^{-1},-\mathrm{C}=\mathrm{O}$ stretching at $1700 \mathrm{~cm}^{-1}$ and $-\mathrm{C}=\mathrm{C}$ stretching at $1600 \mathrm{~cm}^{-1}$. The characteristic peaks of MEA were at $2850 \mathrm{~cm}^{-1}, 1700 \mathrm{~cm}^{-1}$ and $1100 \mathrm{~cm}^{-1}$, which attributed to the stretching vibrations of $-\mathrm{CH}_{2},-\mathrm{C}=\mathrm{O}$ and $-\mathrm{C}-\mathrm{O}-\mathrm{C}-$, respectively. The FTIR spectrum of pure PEGA showed $-\mathrm{CH}_{2}$ stretching at $2800 \mathrm{~cm}^{-1},-\mathrm{C}=\mathrm{O}$ stretching at $1700 \mathrm{~cm}^{-1}$ and $-\mathrm{C}-\mathrm{O}-\mathrm{C}-$ stretching at $1200 \mathrm{~cm}^{-1}$. In the spectrum of PM, both MEA and PEGA characteristic
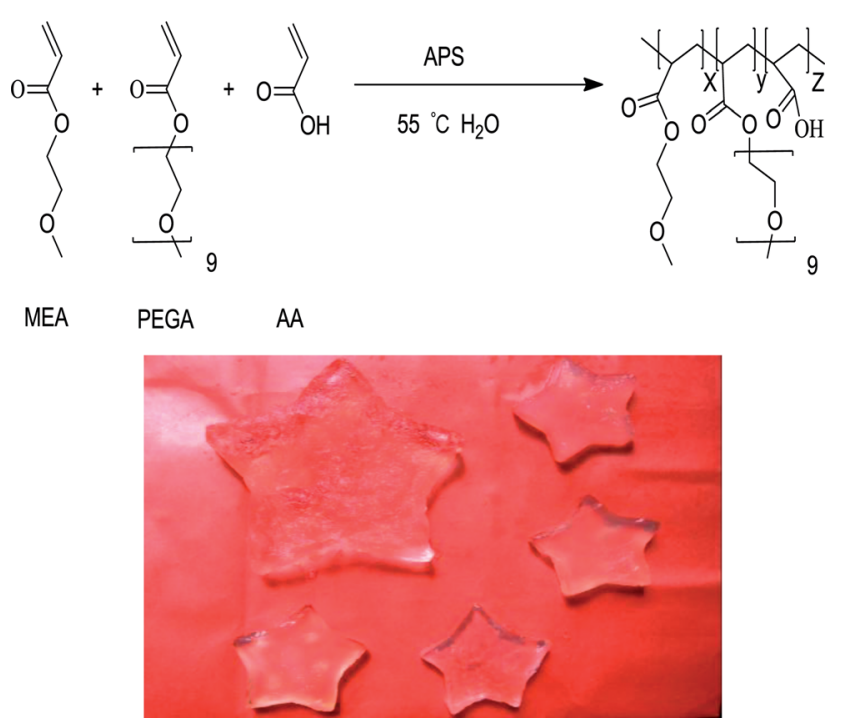

Scheme 1 Schematic produce of hydrogels preparation. peaks were observed, which indicating the PM hydrogel was synthesized. In the spectrum of PMA-1, the characteristic - $\mathrm{OH}$ peak shifted to $3300 \mathrm{~cm}^{-1}$ and became broader. Due to the polymerization, the $-\mathrm{CH}_{2}$ stretching band at $2800 \mathrm{~cm}^{-1}$ and the $-\mathrm{C}=\mathrm{C}$ stretching band at $1480 \mathrm{~cm}^{-1}$ disappeared. The peaks at $1700 \mathrm{~cm}^{-1}$ and $1150 \mathrm{~cm}^{-1}$ were $-\mathrm{C}=\mathrm{O}$ stretching and $-\mathrm{C}-\mathrm{O}-\mathrm{C}-$, respectively, which proved the PMA-1 hydrogels was obtained. For PMA-2, similar spectrum was observed, which suggested the PMA-2 hydrogel was synthesized successfully.

The ${ }^{13} \mathrm{C}$ NMR spectra $(\alpha-\gamma)$ of AA, MEA and PEGA were shown in Fig. 2A. The signals at 175, 136, $128 \mathrm{ppm}$ were assigned to AA $(-\mathrm{C}=\mathrm{O}, \mathrm{C}=\mathrm{C})$. The signals at $168,133,128,60-80 \mathrm{ppm}$ were assigned to MEA $\left(-\mathrm{C}=\mathrm{O}, \mathrm{C}=\mathrm{C},-\mathrm{CH}_{2}\right)$. The signals at 168,133 , 128, 60-80 ppm were assigned to PEGA $\left(-\mathrm{C}=\mathrm{O}, \mathrm{C}=\mathrm{C},-\mathrm{CH}_{2}\right)$. In order to quantitative analyse the content of AA, solid-state ${ }^{13} \mathrm{C}$ cross-polarization/MAS single pulse excitation/MAS NMR experiments were performed on freeze-dried hydrogels samples, and the spectra were shown in Fig. $2 B(\delta-\eta)$. The signals of monomer could be distinguished in Fig. 2A. All hydrogels had been washed 3 times to remove the unreacted monomer. With the increase of the content of AA, the integral area of $-\mathrm{C}=\mathrm{O}$ peaks increased and the $-\mathrm{CH}_{3}$ peaks reduced, which suggested that there were more AA combining with MEA and PEGA. Through titration experiment, ${ }^{19}$ the contents of AA were obtained as 12\% (PMA-1) and 21\% (PMA-2). The results are consistent with the ${ }^{13} \mathrm{C} \mathrm{CP} / \mathrm{MAS}$ NMR results.

\section{The morphology of hydrogels}

The morphology of all hydrogels were observed by SEM and shown in Fig. 3. PM hydrogel showed a rough construct and no pore structure (Fig. 3a). With the introducing of AA, PMA hydrogels became porous morphology, as shown in Fig. 3b-c. With the increasing of AA, the porous became denser and the pore size became smaller.

\section{Mechanical properties}

Both PM and PMA hydrogels are transparent and soft. PM hydrogel was relatively brittle and easy to break, while PMA

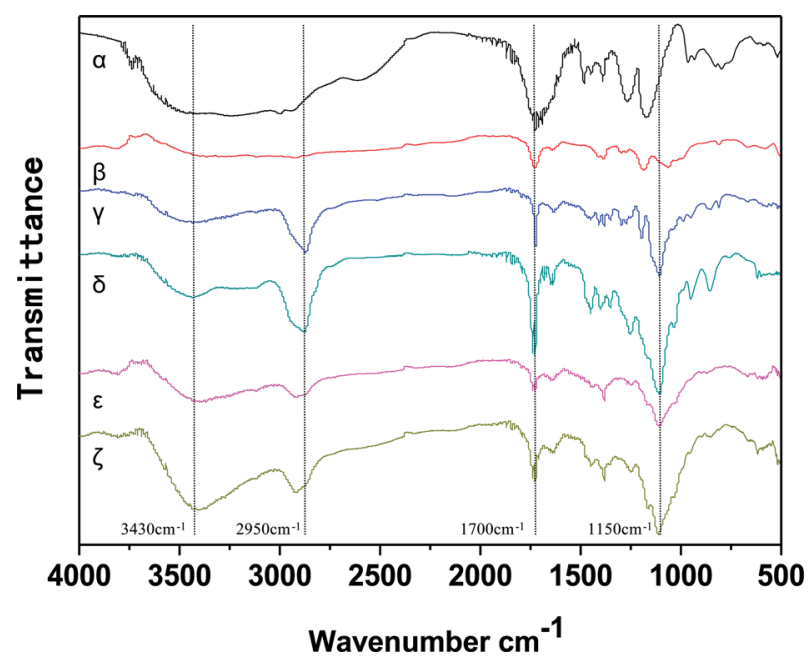

Fig. 1 FTIR spectra of AA $(\alpha), \operatorname{MEA}(\beta), \operatorname{PEGA}(\gamma), \operatorname{PM}(\delta), \operatorname{PMA}-1(\varepsilon)$ and PMA-2 (५). 
A

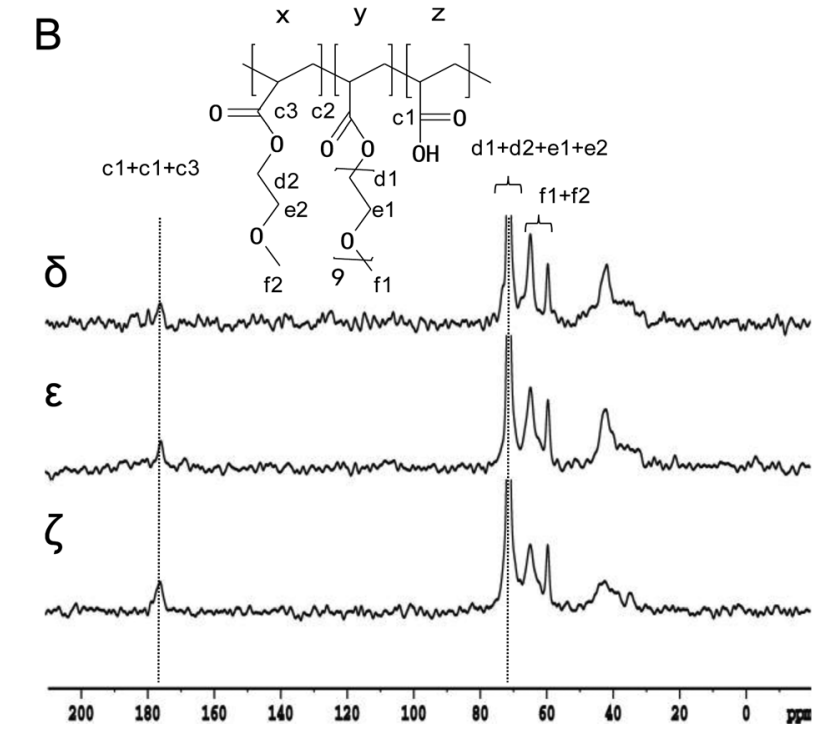

Fig. 2 (A) ${ }^{13} \mathrm{C}$ NMR spectra in $\mathrm{CDCl}_{3}(700 \mathrm{MHz})$ of $\mathrm{AA}(\alpha), \operatorname{MEA}(\beta)$, PEGA $(\gamma)$. (B) ${ }^{13} \mathrm{C} \mathrm{CP/MAS} \mathrm{NMR} \mathrm{spectra}(300 \mathrm{MHz})$ of PM $(\delta)$, PMA-1 $(\varepsilon)$,

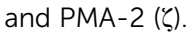

hydrogels showed better elasticity, one can pinch and malaxate it without crumble. To study the mechanical properties of hydrogels, the stress in $50 \%$ strain was chosen to evaluate the mechanical properties of the samples. Fig. 4 shows the compressive stress-strain curves of PM, PMA-1 and PMA-2. It can be observed that the stress-strain curves of PM and PMA
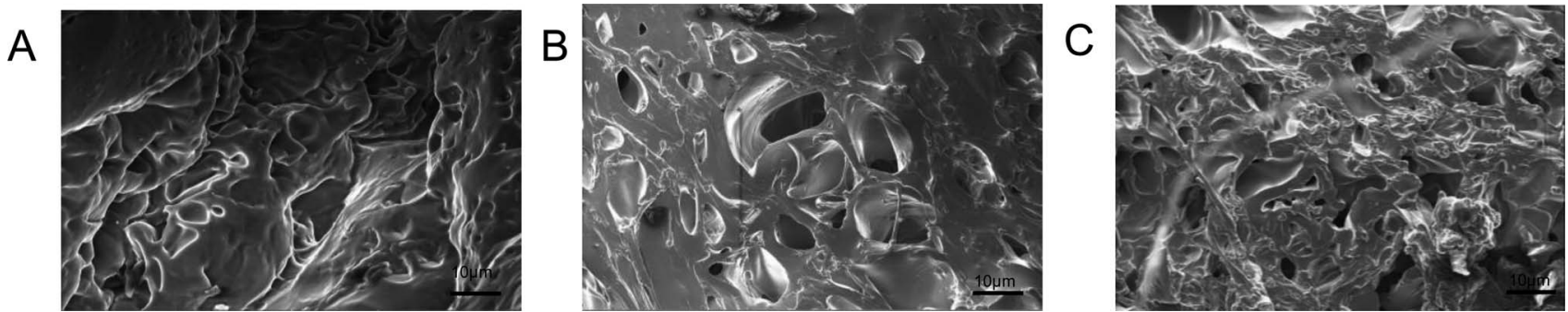

Fig. 3 The SEM image of hydrogels: PM (A), PMA-1 (B) and PMA-2 (C). All the samples were prepared by saturated swelling and freeze-dried. hydrogels were significant different. The stress in $50 \%$ compressive strain of PM hydrogel was only $8.61 \mathrm{kPa}$, while that of PMA hydrogels ranged from $52.74 \mathrm{kPa}$ to $79.84 \mathrm{kPa}$, improved at least 6 times. With the increasing of AA content, the stress in $50 \%$ strain increased. Due to the weak mechanical properties, the application of PM hydrogel is quite limited, and similar hydrogels were normally used as micro hydrogels. ${ }^{17}$ With $50-80$ $\mathrm{kPa}$ elastic modulus, the applications of PMA hydrogels are more extensive, such as adsorption material and drug delivery. ${ }^{20,21}$

\section{Temperature responsiveness}

All the PM and PMA hydrogels showed obvious thermal sensitivity. The temperature responsiveness of the samples was shown in Fig. 5, and the parameters were collected in Table 2. In Fig. 5A, the LCST of PM hydrogel was $63^{\circ} \mathrm{C}$. By introducing AA into the copolymer, the LCST decreased to $58{ }^{\circ} \mathrm{C}$ for PMA-1. With the increase of AA content, the LCST of PMA-2 decreased to $37^{\circ} \mathrm{C}$. As an example, the images of thermal transitions on PMA-2 were exhibited in Fig. $5 \mathrm{~B}$ from $35{ }^{\circ} \mathrm{C}$ to $45^{\circ} \mathrm{C}$. Through changing the monomers ratio, it provided a convenience way to adjust the temperature responsiveness. For PM hydrogel, it took 8 degrees for transmittance decrease from $100 \%$ to $0 \%$ (from $60{ }^{\circ} \mathrm{C}$ to $68^{\circ} \mathrm{C}$ ). While for PMA-1, the corresponding temperature range is $55-61{ }^{\circ} \mathrm{C}$ which showed shaper responsiveness. Especially for the PMA-2, the temperature range is only $37-40{ }^{\circ} \mathrm{C}$, much less than the PNIPAM hydrogels. ${ }^{22}$ This character makes them can be used in conditions requiring higher sensitivity.

When the temperature increased through upon hydrogels' LCST, the swelling ratio of PM and PMAs also exhibited corresponding changes (Fig. 5C). For PM hydrogel, with temperature increased from $25{ }^{\circ} \mathrm{C}$ to $80{ }^{\circ} \mathrm{C}$, a continuous deswelling was observed. While for PMA hydrogels, different trends were shown. With the temperature increasing, the swelling ratio decreased like a two-step exponential. The swelling ratio reduced quickly at first and then came to a plateau. This is the first step. After the short plateau, the swelling ratio decreased sharply again, and then slowed down until reached another plateau. This is the second step.

As we know, water has two different states in swelling hydrogels. One is freedom water and the other is bonded water, according to the different interactions between polymer chains and water molecules. ${ }^{23,24}$ When temperature increased, free water was lost easily. Therefore, the swelling ratio decreased 


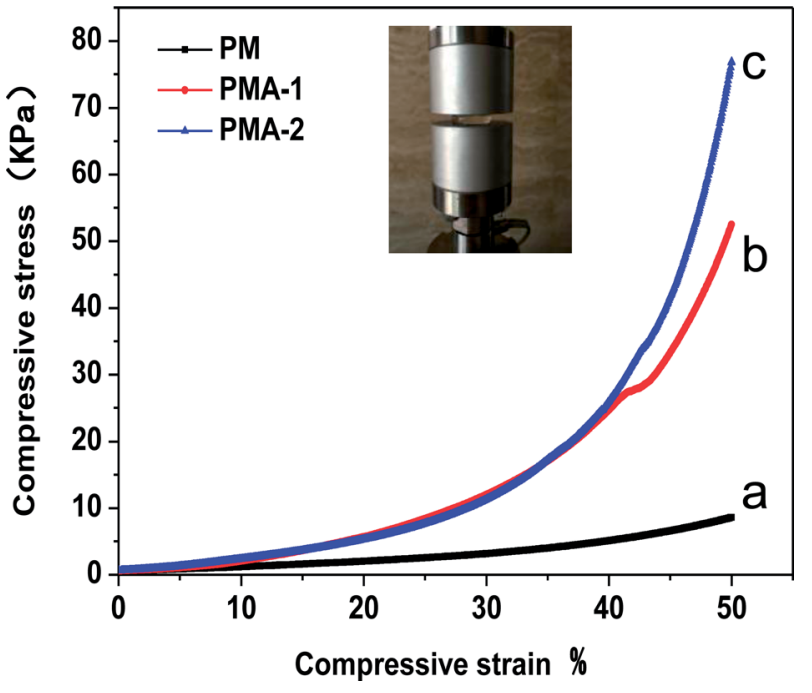

Fig. 4 Compressive stress-strain curve of hydrogels PM (a), PMA-1 (b) and PMA-2 (c). The insetted image was the compressing experiment of PMA-2.

sharply. Meanwhile, there was a great amount of bonded water that was not easy to lose, which led to the first plateau. With the temperature increased close to LCST, polymer chains aggregated, interactions between polymer chains and water molecules weakened. It made much of the bonded water transfer to free water. ${ }^{25,26}$ Thus, with the hydrogel shrinking, those free water molecules were extruded from hydrogel quickly. The swelling ratio decreased sharply again. After that, only strongly bonded water was left in the hydrogel, which presented as the final plateau at the curves.

Regeneration experiments were also performed to study the application of hydrogels. The hydrogels were heated to $80{ }^{\circ} \mathrm{C}$ then cooled to $25^{\circ} \mathrm{C}$. This process was repeated 5 times and the swelling ratio was measured each time. The results were shown in Fig. 5D. After five cycles, the swelling-deswelling properties were maintained more than $90 \%$ and kept stable. These results indicated that PMA hydrogels are good reusable materials.

\section{pH responsiveness of hydrogels}

As our anticipation, by introducing the AA content, the hydrogels may gain $\mathrm{pH}$ responsiveness. Due to the hydrophilic content and protonation of carboxyl group, the volume of hydrogels could extend or shrink following the solution $\mathrm{pH}$ value. The SEM images of PMA-2 hydrogels at different $\mathrm{pH}$ solution were shown in Fig. 6a-c were SEM images of PAM-2 hydrogels with same original volume and shape treated by $\mathrm{pH}$ 4.01, pH 7.4 and pH 9.18 PBS at $25^{\circ} \mathrm{C}$, respectively. At lower $\mathrm{pH}$, the acid solutions caused the dissociation of ionic bonds because of protonation of carboxyl group. At higher $\mathrm{pH}$, due to ionization and hydration, the carboxyl group were COO- forms at an alkaline solution. ${ }^{27}$

The relationship between $\mathrm{pH}$ and swelling ratio of hydrogels was studied. The equilibrium swelling ratio of dried PM, PMA-1 and PMA-2 hydrogels were measured in $\mathrm{pH}=4.01, \mathrm{pH}=7.4$ and $\mathrm{pH}=9.18$ solutions at $25^{\circ} \mathrm{C}$ and collected in Table 2 .

Fig. 7 showed the swelling behaviours of PM and PMA hydrogels. In Fig. 7A, all samples showed low swelling ratio in acidic condition. In neutral and alkali conditions, the swelling ratio of PMA hydrogels highly increased (see Fig. 7B and C), while PM hydrogel remained constant. All the samples remained their shape integrally (see Fig. 7D).

In neutral condition, the swelling ratios of PMA-1 and PMA-2 were 30.9 and $57.4 \mathrm{~g} \mathrm{~g}^{-1}$, respectively, much more than that of PM (14.2). Both PEGA and MEA were not strong hydrophilic molecules. When strong hydrophilic carboxyl group was introduced into the copolymer, the hydrophilic ability of the whole system improved greatly and produced a tight and ionic bonds structure, introducing a large number of water-binding sites. Hence, the swelling ratio was enhanced.

To evaluate the regeneration ability, the hydrogels were alternately put into $\mathrm{pH}=9.18$ and $\mathrm{pH}=4.01$ PBS solutions repeatedly and measured the swelling ratio for 5 times. The results were shown in Fig. 7D. After five cycles, the swellingdeswelling property was still more than $90 \%$ and kept stable. This result indicated that PMA hydrogels were stable and reusable materials.

\section{Adsorption}

Due to the carboxyl groups, the hydrogels are also good special adsorption materials for cationic dyes. The adsorption behaviour of brilliant green was investigated at $25{ }^{\circ} \mathrm{C}$. The adsorption kinetic curves of brilliant green were shown in Fig. 8. Both PMAs and PM samples showed adsorption ability. All PMA samples showed better adsorption ability than PM sample. For the PMA, the adsorption amount was increased with the increasing brilliant green. Through the adsorption equation, the equilibrium adsorption ability of PMA-2 was $0.492 \pm 0.008 \mathrm{mg} \mathrm{mg}^{-1}$, much more than that of PM $0.051 \pm 0.003 \mathrm{mg} \mathrm{mg}^{-1}$. It was also much higher than previous reports (around $0.135 \mathrm{mg} \mathrm{mg}^{-1}$ ). ${ }^{28}$

The outstanding adsorption property of PMA hydrogels were attributed to the negative charged carboxyl group which can combine with the positive charged amino-group. And the porous structure could provide channels for dye molecules freely moving into the hydrogels. ${ }^{29,30}$ With the increasing of AA content, the adsorption capacity for brilliant green was improved from PMA-1 to PMA-2. It was attributed to the increasing combination sites by AA.

As the adsorption kinetic curves of PMA-2 and PM were shown in Fig. 9a. In the first $10 \mathrm{~h}$, the PMA-2 exhibited rapidly adsorption of brilliant green and reached $93 \%$ of the equilibrium adsorption. During the next $5 \mathrm{~h}$, the adsorption amount increased slowly and reached adsorption equilibrium. Compared with PMA-2, the adsorption kinetic of PM reached equilibrium slowly. The rapidly adsorption ability was attribute to the porous structure and the strong interaction between carboxyl group and amino-group. When dried hydrogels were put into the brilliant green solution, through the swelling process, brilliant green easily diffused into PMA and be caught 

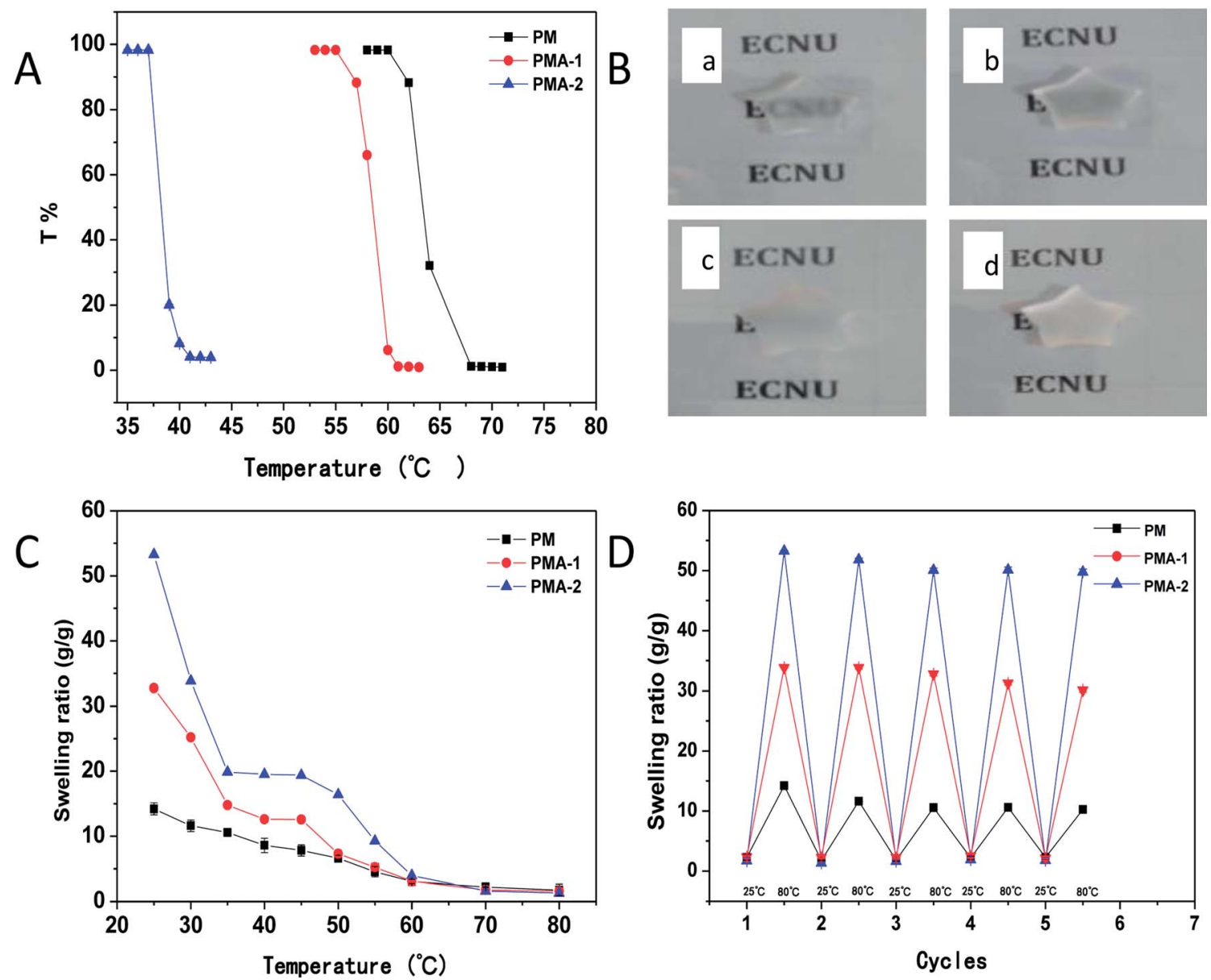

Fig. 5 (A) Temperature response property of hydrogels PM, PMA-1 and PMA-2. (B) The images of hydrogels PMA-2's thermal transitions at $35^{\circ} \mathrm{C}$ (a), $37^{\circ} \mathrm{C}$ (b), $39^{\circ} \mathrm{C}$ (c) and $41^{\circ} \mathrm{C}$ (d), respectively. (C) Swelling property of hydrogels PM, PMA-1 and PMA-2 with temperature. (D) Temperature responsiveness property of PM, PMA-1 and PMA-2 with five cycles.

by carboxyl group. The porous structure of hydrogel improved the dynamics rate.

To further study the adsorption kinetics of brilliant green on PMA-2, the adsorption rate was fitted by kinetic adsorption rate equation as eqn (4) and (5) and the kinetic parameters were listed in Table 3.

$$
\begin{gathered}
Q_{t}=Q_{\mathrm{e}}-Q_{\mathrm{e}^{-k_{1} t}} \\
Q_{t}=\frac{k_{2} Q_{\mathrm{e}}{ }^{2} t}{1+t k_{2} Q_{\mathrm{e}}}
\end{gathered}
$$

$Q_{\mathrm{e}}\left(\mathrm{mg} \mathrm{mg}^{-1}\right)$ is equilibrium. $Q_{t}\left(\mathrm{mg} \mathrm{mg}^{-1}\right)$ is the amount of brilliant green adsorbed on PMA-2 at time $t . k_{1}$ is the rate constant of pseudo-first-order model. $k_{2}$ is the rate constant of pseudo-second-order model.

Table 2 Properties of PM and PMA samples

\begin{tabular}{llllll}
\hline Sample & $\begin{array}{l}\text { Stress } \\
(\mathrm{kPa})\end{array}$ & $\begin{array}{l}\text { LCST } \\
\left({ }^{\circ} \mathrm{C}\right)\end{array}$ & $\begin{array}{l}\text { SR }\left(\mathrm{g} \mathrm{g}^{-1}\right), \\
(\mathrm{pH} \mathrm{4.01)}\end{array}$ & $\begin{array}{l}\text { SR }\left(\mathrm{g} \mathrm{g}^{-1}\right), \\
(\mathrm{pH} \mathrm{7.4})\end{array}$ & $\begin{array}{l}\mathrm{SR}\left(\mathrm{g} \mathrm{g}^{-1}\right), \\
(\mathrm{pH} \mathrm{9.18})\end{array}$ \\
\hline PM & 8.61 & 63 & 12.4 & 14.2 & 14.6 \\
PMA-1 & 52.47 & 58 & 21.1 & 30.9 & 51.2 \\
PMA-2 & 79.84 & 37 & 17.3 & 57.4 & 95.3
\end{tabular}

Compared with pseudo-first-order, the adsorption process of PMA-2 was in accord with the characteristics of the pseudosecond-order. It indicated that the adsorption process could be a chemical adsorption process with a fast adsorption beginning.

Fig. 9b was the isothermal adsorption curve for brilliant green on PMA and PM. Compared Langmuir and Freundlich adsorption equilibrium as following eqn (6) and (7), the results of Langmuir and Freundlich adsorption were shown in Table 4.

$$
\begin{aligned}
\frac{1}{Q_{\mathrm{e}}} & =\frac{1}{Q_{\mathrm{m}}}+\frac{1}{Q_{\mathrm{m}} b} \frac{1}{C_{\mathrm{e}}} \\
\ln Q_{\mathrm{e}} & =\frac{1}{n} \ln C_{\mathrm{e}}+\ln K_{\mathrm{F}}
\end{aligned}
$$

$C_{\mathrm{e}}$ is the equilibrium concentration of brilliant green in solution ( $\mathrm{mg} \mathrm{mL}^{-1}$ ). $Q_{\mathrm{m}}$ is the maximum adsorption capacity of the adsorbent $\left(\mathrm{mg} \mathrm{mg}^{-1}\right) . b$ is the Langmuir adsorption equilibrium constant $\left(\mathrm{mL} \mathrm{mg}^{-1}\right) . K_{\mathrm{F}}$ and $1 / n$ are the Freundlich characteristic constants.

The correlation coefficient $R^{2}$ of Langmuir and Freundlich were close to 1 , which suggested that the adsorption process on PMA-2 was the interaction of physical adsorption and chemical 

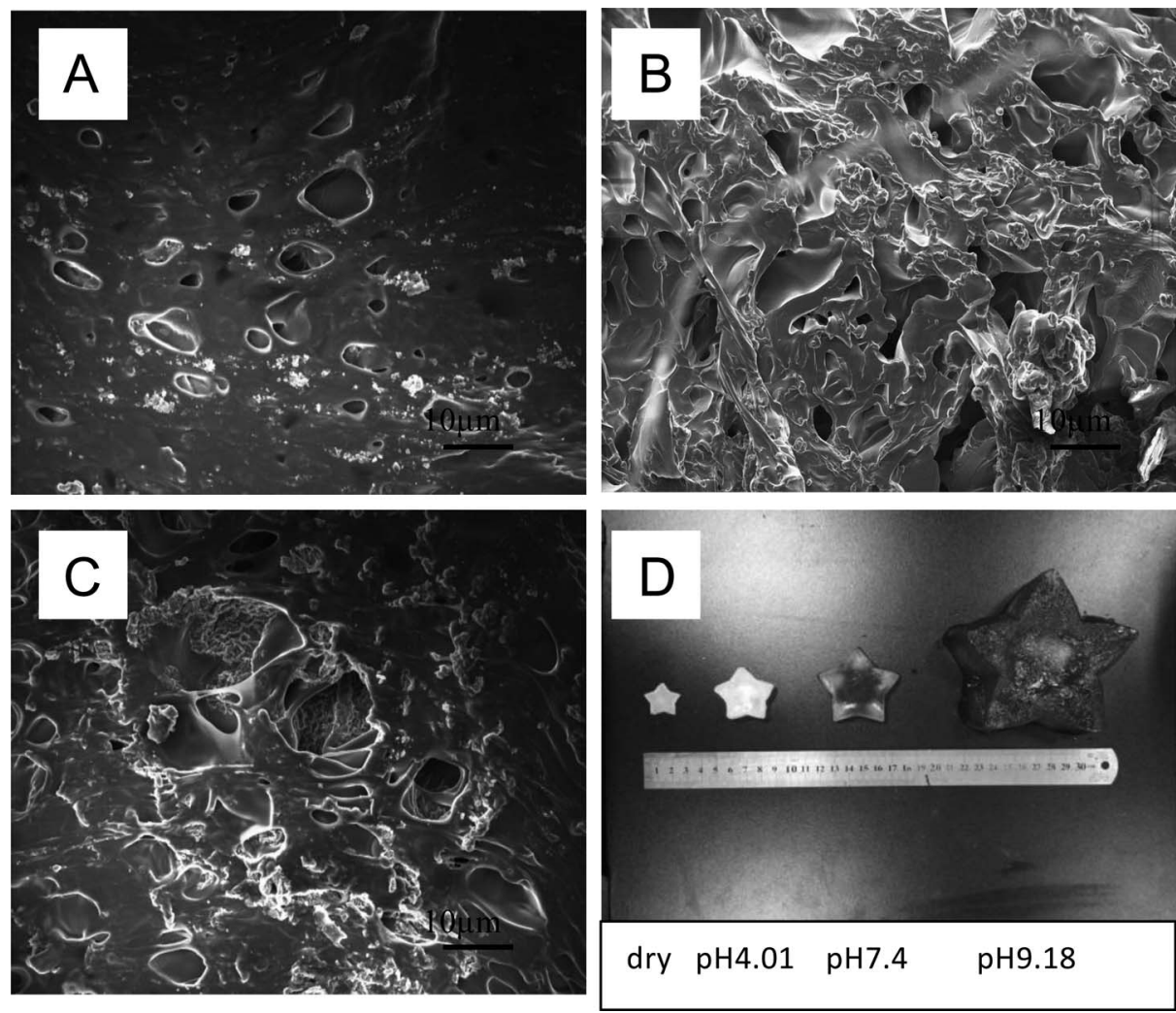

Fig. 6 The SEM images of PMA-2 hydrogels in $\mathrm{pH}=4.01$ solution (A), $\mathrm{pH}=7.4$ solution (B) and $\mathrm{pH}=9.18$ solution $(\mathrm{C})$ at $25^{\circ} \mathrm{C}$ by saturated swelling and then freeze dried. (D) The images of PMA-2 hydrogel after swelling in PBS with different $\mathrm{pH}$.
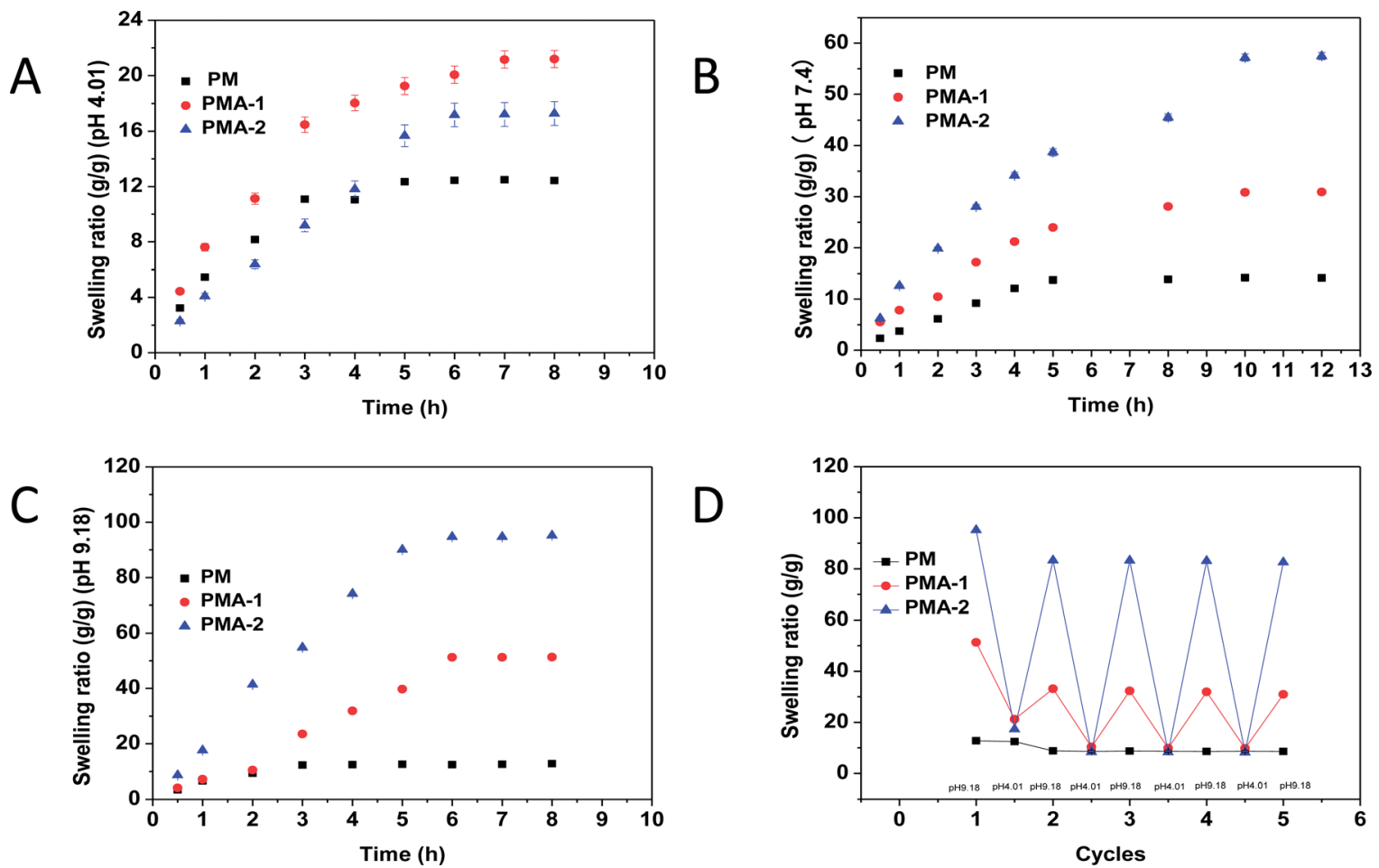

Fig. 7 Swelling property of hydrogels $\mathrm{PM}, \mathrm{PMA}-1$ and $\mathrm{PMA}-2$ in $\mathrm{pH}=4.01$ solution (A), $\mathrm{pH}=7.4$ solution (B) and $\mathrm{pH}=9.18$ solution (C). (D) $\mathrm{pH}$ responsiveness property of $\mathrm{PM}, \mathrm{PMA}-1$ and $\mathrm{PMA}-2$ with five cycles. 
A

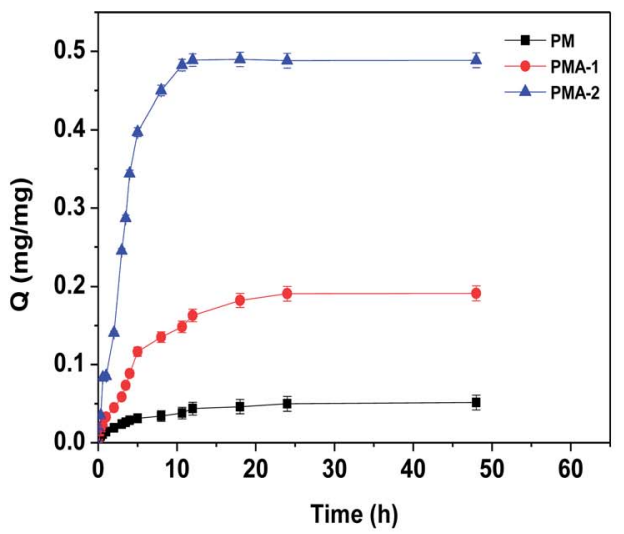

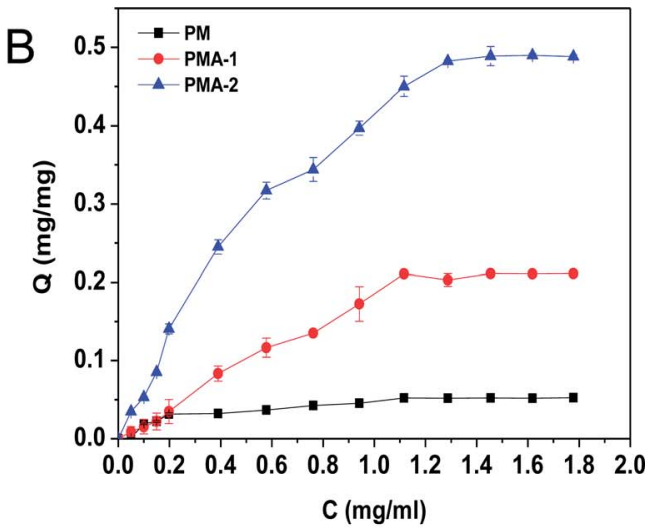

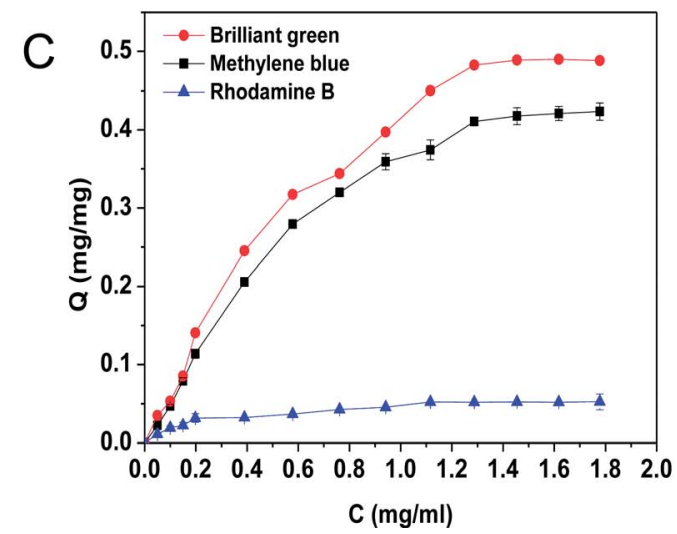

Fig. 8 (A) Adsorption kinetic of brilliant green on PM, PMA-1 and PMA-2. (B) Static adsorption isotherms of brilliant green on PM, PMA-1 and PMA-2. (C) Static adsorption isotherms of brilliant green, methylene blue and rhodamine B on PMA-2.

adsorption. ${ }^{31}$ It indicated that the adsorption was not a monolayer adsorption and there was strong interaction between the brilliant green and PMA-2. The adsorption intensity $(1 / n)^{32}$ of Freundlich was the adsorption intensity and surface heterogeneity. The $1 / n$ was 0.253 . It suggested that the brilliant green could be adsorbed easily by PMA-2.

We also studied the adsorption ability of PMA-2 hydrogel on methylene blue with amino-group and rhodamine $\mathrm{B}$ with carboxyl group (see Fig. 8C). Compared with $0.42 \mathrm{mg} \mathrm{mg}^{-1}$ of methylene blue,$^{33,34}$ the adsorption of rhodamine $\mathrm{B}$ was quite low, which attributed to the weak interaction between PMA and rhodamine $\mathrm{B}$. The excellent adsorption ability indicated that PMA hydrogels had a wide use for selective adsorption of cationic organic dyestuff.

\section{Release and reutilization}

For the organic dyestuff adsorption materials, the desorption and regeneration were attractive properties. Due to the stimuliresponsive properties of the PMA hydrogels, we assumed that the adsorbed dye molecules may be released under fitful
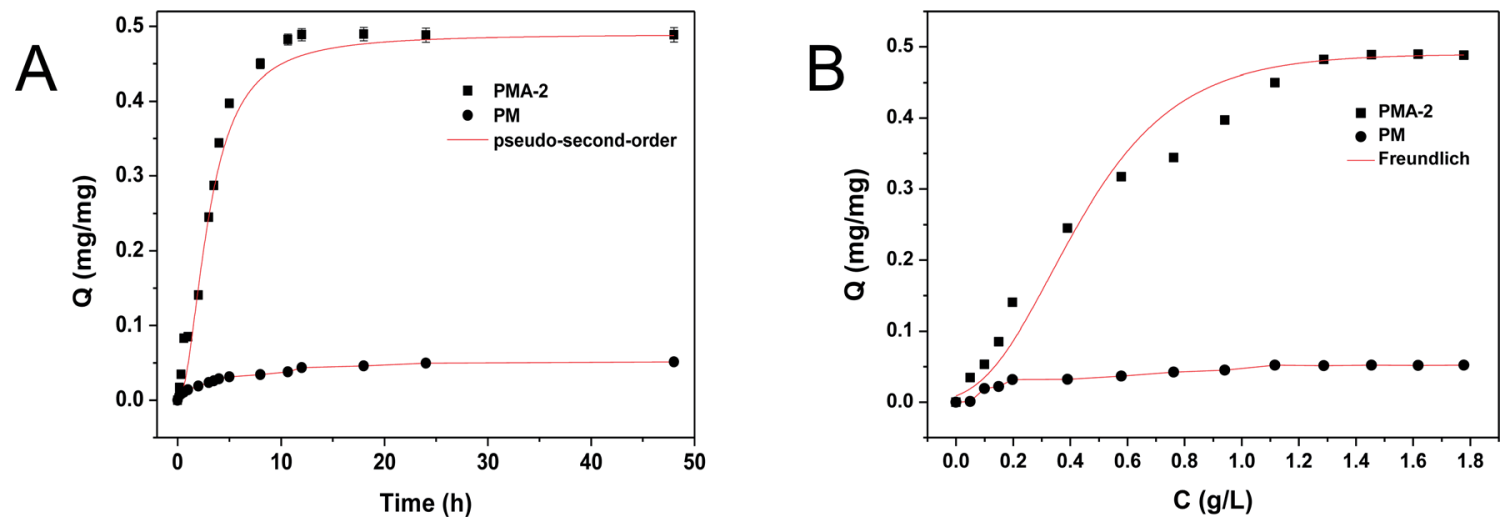

Fig. 9 (A) Static adsorption isotherms for the adsorption process of brilliant green by PMA-2. (B) Adsorption kinetics for the adsorption process of brilliant green by PMA-2. 
Table 3 Kinetics data for the pseudo-first-order and pseudo-second-order rate equation at $25^{\circ} \mathrm{C}$

\begin{tabular}{|c|c|c|c|c|c|c|c|}
\hline & $Q_{\mathrm{e}}\left(\mathrm{mg} \mathrm{mg}^{-1}\right)$ & \multicolumn{3}{|c|}{ Pseudo-first-order } & \multicolumn{3}{|c|}{ Pseudo-second-order } \\
\hline PM & $0.051 \pm 0.003$ & 0.049 & 0.0013 & 0.937 & 0.048 & 0.0011 & 0.985 \\
\hline
\end{tabular}

Table 4 Langmuir and Freundlich data for the adsorption of brilliant green on the PMA-2 at $25^{\circ} \mathrm{C}$

\begin{tabular}{llllllll}
\hline & \multicolumn{2}{l}{ Langmuir } & & \multicolumn{3}{l}{ Freundlich } \\
\cline { 2 - 5 } Adsorption & $Q_{\mathrm{m}}\left(\mathrm{mg} \mathrm{mg}^{-1}\right)$ & $b$ & $R^{2}$ & & $1 / n$ & $K_{\mathrm{F}}$ \\
\hline PMA-2 & $0.494 \pm 0.006$ & 0.865 & 0.964 & 0.253 & 0.324 \\
\hline
\end{tabular}

conditions. Thus, the release behaviour was studied and the results were shown in Fig. 10. Using brilliant green@PMA-2 as an example, the releasing properties at different $\mathrm{pH}$ and different temperature were studied. From Fig. 10A we could see that the releasing capacity at $\mathrm{pH} 4.01$ was more than that at $\mathrm{pH}$ 7.4 and $\mathrm{pH} 9.18$ at room temperature. At $\mathrm{pH} 4.01$, almost $80 \%$ of brilliant green was released within $50 \mathrm{~h}$ at room temperature. While only $18 \%$ and $30 \%$ were released at $\mathrm{pH} 7.4$ and $\mathrm{pH} 9.18$, respectively. It was because the brilliant green located on the surface could release quickly into the solution in the first $10 \mathrm{~h}$. According to the $\mathrm{pH}$ swelling experiments, the lower $\mathrm{pH}$ could improve the deswelling and lower the electrostatic attraction between PMA-2 and brilliant green, which drove more brilliant green molecules to release from hydrogels. Therefore, the brilliant green could be controlled release from hydrogels by $\mathrm{pH}$.

In consideration of thermal sensitive, the release behaviour at different temperature was also researched. In Fig. 10B, it could be found the elevated temperature improved the released content from $80 \%$ to $95 \%$ at $\mathrm{pH} 4.01$. As we know, the PMA hydrogels have LCST, above this temperature, polymer chains aggregate and the hydrogels shrink. Moreover, increasing temperature also accelerated the molecular motion and reduced the releasing time. For example, at $50{ }^{\circ} \mathrm{C}(\mathrm{pH} 4.01)$, it took only $8 \mathrm{~h}$ to release $90 \%$ brilliant green, while at $25{ }^{\circ} \mathrm{C}$, it took $50 \mathrm{~h}$ to release $80 \%$. (Fig. 10A). Hence, after adsorption of the dyestuff, the PMA hydrogels could be easily reused by desorption.

As we can see from Fig. 10B, the releasing rates are almost the same at temperature higher than $65^{\circ} \mathrm{C}$, thus we choose $\mathrm{pH}$ 4.01 and $65{ }^{\circ} \mathrm{C}$ as desorption conditions. Then, the adsorptiondesorption behavior of brilliant green on PMA-2 was studied. Adsorption was performed at neutral condition room temperature. As shown in Fig. 10C, after five cycles, the adsorption ability remained $90 \%$ of the original and kept stable. These results indicated that the PMA-2 hydrogels had good regeneration.

\section{Conclusions}

In this work, a serious of dual-responsive copolymeric PMA hydrogels were successfully synthesized. The PMA hydrogels not only provided intelligent temperature and $\mathrm{pH}$ responsiveness but also had good mechanical properties. With the stimulation of $\mathrm{pH}$ and temperature, the hydrogels showed the excellent repeatable swelling and deswelling properties. The LCST of hydrogels was controllable (from $37^{\circ} \mathrm{C}$ to $58{ }^{\circ} \mathrm{C}$ ) and the mechanical property was quite good (79.84 $\mathrm{kPa}$ in $50 \%$ compressive strain). Because of the carboxyl group, the hydrogels were applied in adsorbing cationic organic dyes like brilliant green $\left(0.49 \mathrm{mg} \mathrm{mg}^{-1}\right)$ and methylene blue $\left(0.42 \mathrm{mg} \mathrm{mg}^{-1}\right)$. The PMA-2 hydrogel also could
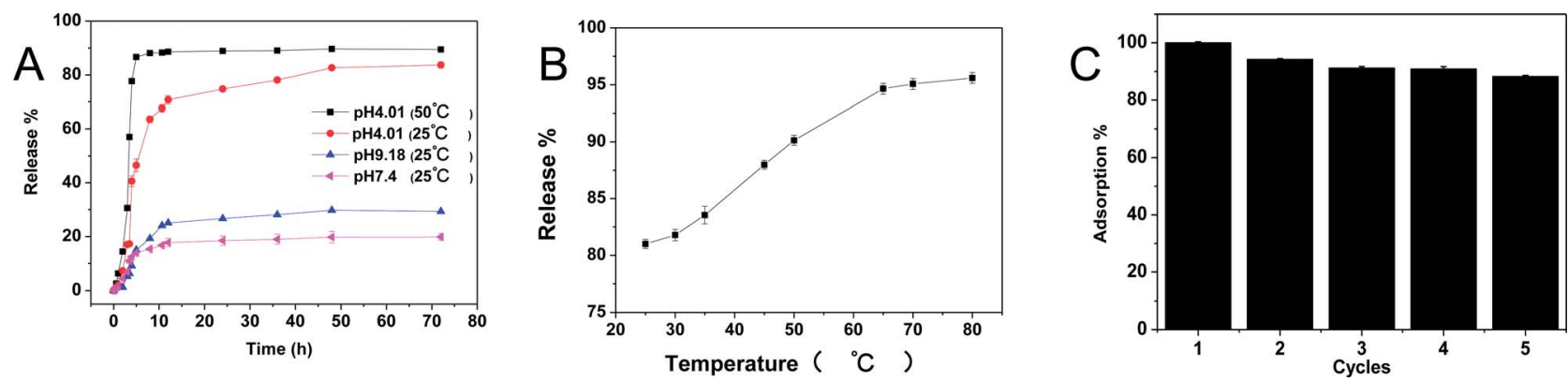

Fig. 10 (A) Time dependence of SBC release from PMA-2 hydrogels in PBS solution ( $\mathrm{pH}=4.01,7.4,9.18$ ) at different temperature. (B) Effect of temperature on release. (C) The regeneration of PMA-2 on brilliant green during five cycles $\left(\mathrm{pH} 4.01 \mathrm{PBS}\right.$ solution and $\left.50{ }^{\circ} \mathrm{C}\right)$. 
easily release nearly $95 \%$ brilliant green at $\mathrm{pH} 4.01$ and $65{ }^{\circ} \mathrm{C}$ during $8 \mathrm{~h}$. Moreover, it also had good regeneration ability and kept $90 \%$ adsorption property after five cycles. In a word, PMA hydrogels are good adsorption materials with high capacity, controllable releasing and good reusability. Besides, with these features, these PMA hydrogels would have wild potential as multifunctional materials in different areas.

\section{Conflicts of interest}

There are no conflicts to declare.

\section{Acknowledgements}

This study was supported by National Natural Science Foundation of China (No. 51273067, 21544003)

\section{Notes and references}

1 Y. Tang, Y. Du, X. Hu, X. Shi and J. F. Kennedy, Carbohydr. Polym., 2007, 4, 491-499.

2 Y. Luo, Y. Guo, X. Gao, B. Li and T. Xie, Adv. Mater., 2013, 5, 743-748.

3 A. Sannino, C. Demitri and M. Madaghiele, Materials, 2009, 2, 353.

4 M. Behl, M. Y. Razzaq and A. Lendlein, Adv. Mater., 2010, 31, 3388-3410.

5 I. Bellin, S. Kelch and A. Lendlein, J. Mater. Chem., 2007, 28, 2885-2891.

6 Y. Wu, J. Hu, C. Zhang, J. Han, Y. Wang and B. Kumar, J. Mater. Chem. A, 2015, 1, 97-100.

7 Q. Zhao, H. J. Qi and T. Xie, Prog. Polym. Sci., 2015, 49, 79120.

8 H. Jia, Z. Huang, Z. Fei, P. J. Dyson, Z. Zheng and X. Wang, ACS Appl. Mater. Interfaces, 2016, 45, 31339-31347.

9 C. Ohm, M. Brehmer and R. Zentel, Adv. Mater., 2010, 31, 3366-3387.

10 K. Shi, Z. Liu, Y. Wei, W. Wang, X. J. Ju, R. Xie and L. Y. Chu, ACS Appl. Mater. Interfaces, 2015, 49, 27289-27298.

11 L. Zha, B. Banik and F. Alexis, Soft Matter, 2011, 13, 59085916.

12 P. S. K. Murthy, M. Y. Murali, K. Varaprasad, B. Sreedhar and R. K. Mohana, J. Colloid Interface Sci., 2008, 2, 217-224.

13 X. Zhang, Y. Yang and T. Chung, J. Colloid Interface Sci., 2002, 1, 105-111.
14 Y. Xiao, X. Gong, Y. Kang, Z. Jiang and S. Zhang, Chem. Commun., 2016, 70, 10609-10612.

15 H. Zhang, Y. Zhang, L. He, B. Yang, S. Zhu and M. Yao, Colloid Polym. Sci., 2016, 12, 1959-1967.

16 Z. M. O. Rzaev, S. Dinçer and E. Pişkin, Prog. Polym. Sci., 2007, 5, 534-595.

17 G. Liu, Q. Qiu and Z. An, Polym. Chem., 2012, 2, 504-513.

18 H. L. Huang, X. H. Wang, H. Ge and M. Xu, ACS Sustainable Chem. Eng., 2016, 6, 3334-3343.

19 H. Ge, H. L. Huang, M. Xu and Q. Chen, Cellulose, 2016, 4, 2527-2537.

20 N. S. Johari, I. Ahmad and N. Halib, Chem. Biochem. Eng. Q., 2012, 26, 399-404.

21 K. Haraguchi and T. Takehisa, Adv. Mater., 2002, 16, 11201124.

22 X. Feng, K. Zhang, P. Chen and X. Sui, Macromol. Rapid Commun., 2016, 13, 1939-1944.

23 W. B. Li, F. Xue and R. S. Cheng, Acta Polym. Sin., 2006, 5, 671-675.

24 G. X. Tan and Y. D. Cui, Polym. Mater. Sci. Eng., 2005, 2, 253256.

25 Y. Zhao, H. Su, L. Fang and T. Tan, Polymer, 2005, 14, 53685376.

26 G. R. Mahdavinia, A. Pourjavadi, H. Hosseinzadeh and M. J. Zohuriaan, Eur. Polym. J., 2004, 7, 1399-1407.

27 R. R. Haikal, A. M. Elmansi, P. Ali, Y. S. Hassan and M. H. Alkordi, RSC Adv., 2016, 48, 42307-42312.

28 L. Y. Kong, F. X. Qiu, Z. Y. Zhao, X. Y. Zhang, T. Zhang, J. M. Pan and D. Y. Yang, J. Cleaner Prod., 2016, 137, 51-59.

29 M. P. Tavlieva, S. D. Genieva, V. G. Georgieva and L. T. Vlaev, J. Colloid Interface Sci., 2013, 409, 112-122.

30 M. S. U. Rehman, M. Munir, M. Ashfaq, M. Rashid, M. F. Nazar, M. Danish and J. I. Han, Chem. Eng. J., 2013, 228, 54-6231.

31 L. Xie, J. Guo, Y. Zhang and S. Shi, J. Agric. Food Chem., 2014, 62, 8221-8228.

32 M. Zhang, R. Wang, Z. Shi, X. Huang, W. Zhao and C. Zhao, J. Hazard. Mater., 2017, 322, 499-507.

33 R. Han, J. Zhang, P. Han, Y. Wang, Z. Zhao and M. Tang, Chem. Eng. J., 2009, 3, 496-504.

34 D. Kavitha and C. Namasivayam, Bioresour. Technol., 2007, 1, 14-21. 